\section{El acercamiento de la provincia de Santa Fe a Kuwait y Emiratos Árabes Unidos. Un ejemplo de la activa paradiplomacia santafecina (2007-2017)}

\author{
A abordagem da província de Santa Fe ao Kuwait e a \\ Emirados Árabes Unidos. Um exemplo da paradiplomacia \\ ativa de santafecina (2007-2017)
}

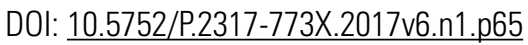

Ornela Fabani ${ }^{1}$

recebido em: 06\01\2017

Aprovado em: 13\11\2017

\section{RESUMEN}

En el marco de un escenario internacional atravesado por el fenómeno de la globalización, en las últimas décadas los actores subnacionales han comenzado a encontrar espacios para desarrollar su acción externa. De esta forma, lo que inicialmente fueron hechos aislados han cobrado visos de cotidianeidad mientras que, paralelamente, dichas acciones han dejado de ser exclusivas de unos pocos actores subnacionales para expandirse y adoptar diferentes modalidades e intensidades. En este marco nos interesa atender al acercamiento de la provincia de Santa Fe a Emiratos Árabes Unidos (EAU) y Kuwait, dos actores pertenecientes a una región lejana, con los cuales la Argentina en su conjunto no ha tenido un vínculo de primera línea a través del tiempo. Dicho esto, nuestro trabajo apunta a indagar en los objetivos que persigue, las acciones en las que se plasma y los avances que se han logrado a partir del acercamiento de la provincia de Santa Fe a Kuwait y EAU en el periodo que se extiende entre 2007 y 2017. Con tal fin recurriremos a un abordaje preponderantemente cualitativo fundado tanto en fuentes primarias como secundarias.

Palabras clave: paradiplomacia - actores subnacionales - Santa Fe - Kuwait Emiratos Árabes Unidos

\section{RESUMo}

No marco de um cenário internacional atravessado pelo fenômeno da globalização, nas últimas décadas os atores subnacionais começaram a encontrar espaços para desenvolver sua ação externa. Dessa forma, os eventos inicialmente isolados assumiram o cotidiano e, ao mesmo tempo, deixaram de ser exclusivos de alguns atores subnacionais para expandir e adotar diferentes modalidades e intensidades. Neste contexto, estamos interessados em abordar a abordagem da província de Santa Fé para os Emirados Árabes Unidos (EAU) e Kuwait, dois atores pertencentes a uma região distante, com a qual a Argentina como um todo não teve um elo de primeira linha do tempo. Dito isto, o nosso trabalho tem como objetivo investigar os objetivos perseguidos, as ações em
1. Doctora en Relaciones Internacionales por la Universidad Nacional de Rosario (UNR), Becaria posdoctoral del Consejo Nacional de Investigaciones Científicas y Técnicas (CONICET). Docente de la cátedra Política Internacional de la Facultad de Ciencia Política y Relaciones Internacionales, UNR. Miembro del Centro de Estudios en Relaciones Internacionales de Rosario (CERIR) y del Departamento de Medio Oriente del Instituto de Relaciones Internacionales (IRI) de La Plata. Orcid: 0000-0002-6879-1908 
que toma forma e os progressos realizados desde a aproximação da província de Santa Fé ao Kuwait e aos Emirados Árabes Unidos no período que se estende entre 2007 e 2007. e 2017. Para este fim, recorreremos a uma abordagem predominantemente qualitativa, baseada em fontes primárias e secundárias.

Palavras-chave: paradiplomacia - atores subnacionais - Santa Fé - Kuwait Emirados Árabes Unidos.

Introducción

En el marco de un escenario internacional atravesado por el fenómeno de la globalización, en las últimas décadas los actores subnacionales han comenzado a encontrar espacios para desarrollar su acción externa. De esta forma, lo que inicialmente fueron hechos aislados han cobrado visos de cotidianeidad mientras que, paralelamente, dichas acciones han dejado de ser exclusivas de unos pocos actores subnacionales para expandirse y adoptar diferentes modalidades e intensidades. Como correlato, han surgido nuevos ámbitos de relaciones que ya no se circunscriben a aquellos que tienen por protagonista al Estado Nación, en los que las regiones, provincias y ciudades asumen un rol central. En la Argentina este proceso comenzó a perfilarse tímidamente en los ochenta para profundizarse durante la década del noventa. En tanto, la acción externa de los actores subnacionales ha tenido diversos fines, desde obtener financiamiento externo, fomentar el comercio o atraer inversiones, a impulsar el turismo así como también la cooperación en las más variadas áreas.

Ahora, si bien la acción externa de los actores subnacionales se ha multiplicado en los últimos tiempos, convirtiéndose la paradiplomacia en un fenómeno ampliamente extendido, en este caso llama nuestra atención el acercamiento de la provincia de Santa Fe a Emiratos Árabes Unidos (EAU) y Kuwait. Ello en virtud de que se trata de actores pertenecientes a una región lejana, con los cuales Santa Fe no sólo no comparte fronteras sino que la separan miles de kilómetros de distancia. Amén de ello, no existe entre la provincia de Santa Fe y dichos países una idiosincrasia compartida, puesto que en términos religiosos, tanto como políticos y culturales, la Argentina en su conjunto encuentra marcadas diferencias con los Estados que componen el espacio que ha dado en llamarse Medio Oriente. Por último, destacamos lo inusual de estos contactos ya que los países pertenecientes a la citada región inclusive no han ocupado un espacio jerarquizado dentro de la agenda de política exterior del Estado nacional. Esto pese a que la Argentina ha recibido un flujo importante de inmigrantes árabes entre finales del siglo XIX y mediados del siglo XX, los cuales, cabe aclarar, no han sido originarios de los países que aquí se encuentran en consideración.

En base a lo hasta aquí expuesto, nos preguntamos: cuáles son objetivos que persigue la provincia de Santa Fe al acercarse a Kuwait y EAU? Por medio de qué acciones se plasma dicho acercamiento? Qué avances se han logrado a partir del incremento de los contactos entre las partes?

Dicho esto, nuestro trabajo apunta a indagar en los objetivos que persigue, las acciones en las que se plasma y los avances que se han logra- 
do a partir del acercamiento de la provincia de Santa Fe a Kuwait y EAU en el periodo que se extiende entre 2007 y 2017.

Al respecto, vale destacar que hemos escogido este recorte temporal pues el mismo coincide con los inicios de la gestión del gobernador Hermes Binner $(2007,2011)$ cuyo gobierno fue artífice de los primeros contactos con los citados actores del golfo. En tanto, decidimos extender el estudio hasta 2017 con vistas a analizar la evolución de estos vínculos que, pese a los cambios de gobierno, han tenido continuidad en el tiempo hasta la actualidad.

A modo de aproximación teórica al tema de investigación, es importante señalar que por unidades subnacionales entendemos "unidades institucionales o niveles del Poder Ejecutivo, que son componentes de un Estado nacional: ciudades, estados, regiones, provincias, municipios u otros poderes locales" (FRONZAGLIA 2005 apud. CALVENTO, 2014, p. 301). Ahora bien, entendemos que la acción externa de estos actores ingresa en el ámbito de la paradiplomacia.

Al respecto, Duchacek (1984) comprende a la misma como las acciones de los gobiernos no centrales con centros culturales, comerciales e industriales de otros Estados incluyendo relaciones con los gobiernos extranjeros. De esta forma, el autor diferencia paradiplomacia de lo que se entiende por diplomacia per se en que la primera se focaliza en acciones más específicas sin tener por fin representar a una entidad territorial como un todo.

Por su parte, De Marsilio (2006) da cuentas de una serie de tópicos o materias que las unidades subnacionales desarrollan en la esfera internacional. Entre ellos podemos mencionar los temas económicos que incluyen las cuestiones comerciales (promoción del comercio exterior e, incluso, de la inversión extranjera directa) y financieras; las cuestiones relativas a la infraestructura, más comunes a las entidades fronterizas; las cuestiones educativas, culturales y sociales. Asimismo, el autor repara en que estos actores también atienden a lo que clasifica como cuestiones varias, que incluyen temas sanitarios, medioambientales y de cooperación judicial, entre otros.

De cualquier forma, De Marsilio (2006) destaca que el relacionamiento económico de los entes subnacionales es el fenómeno más destacado de su accionar externo. En esta misma dirección, Zubelzú; Colacrai (2004) señalan que ciertos actores subnacionales parecen sintonizar con la tendencia a comportarse como lo que Rosencrance (1986) denomina Estados comercialistas. En este sentido, como veremos a continuación, la provincia de Santa Fe no se presenta como una excepción.

En otro orden, a los fines de este trabajo también resulta relevante la clasificación de García Segura (1996) quien ya no se detiene en las áreas de acción de las unidades subnacionales sino en los distintos tipos de acción externa que protagonizan las mismas. De esta forma, la autora diferencia la acción externa de los actores subnacionales: según el nivel de implicación en el sistema internacional (presencia directa o indirecta), acorde al nivel de institucionalización del vínculo (contactos formales o informales), en base a la relación con la actividad exterior del Estado nacional (cooperación, conflicto o actuación paralela) y, a su vez, atendiendo a un criterio geopolítico (transfronteriza, transregional y global). 
La presencia directa refiere a aquellos casos en los cuales la unidad subnacional actúa sin intermediación de un tercero, como es el caso del Estado nacional. En tanto, cuando el actor subnacional intenta incidir en la política nacional y presiona sobre el actor estatal, sin estar directamente presente en la arena internacional, se habla de presencia indirecta.

Las acciones informales son todas aquellas que desarrolla el actor subnacional sin requerir de un alto grado de institucionalización o del establecimiento de procedimientos específicos, estas pueden ir desde los contactos informales entre grupos de la elite a comidas de negocios o comunicaciones telefónicas. Mientras tanto, entre las acciones formales se encuentran las misiones comerciales e institucionales, la apertura de oficinas comerciales en el exterior, la recepción de misiones $u$ autoridades extranjeras, entre otras.

En base a la relación entre el gobierno central y la unidad subnacional en la que se enmarque la actuación externa de esta última la actividad exterior de la misma podrá ser de cooperación, conflicto o de actuación paralela con el Estado nacional. De esta forma, existirá cooperación cuando los objetivos de ambas partes resulten coincidentes y actuación paralela cuando sin existir conflicto entre las partes su acción externa no resulte coordinada. Esta situación puede ser producto de que los actores estatal y subnacional posean intereses inconexos o directamente de la inexistencia de un interés compartido. En tanto, el conflicto emergerá cuando el actor subnacional no juzgue sus intereses adecuadamente representados en el exterior lo cual podrá incluso derivar en que este último decida desarrollar su accionar externo desatendiendo las directrices del gobierno central. En este sentido, Kincaid (1990) afirma que el conflicto derivado del accionar externo de las unidades subnacionales se encuentra estrechamente ligado a los patrones de cooperación y conflicto vigentes al interior del propio Estado, no resultando fruto de una dinámica especial o independiente sino, por el contrario, de la reproducción del conflicto que se suscita en otros campos de las relaciones centrales-subnacionales.

Por último, siguiendo el esquema de Duchacek (1984), García Segura (1996) diferencia: paradiplomacia regional transfronteriza, que involucra contactos entre actores subnacionales que comparten una frontera; paradiplomacia transregional, que alude a los vínculos entre gobiernos no centrales que no son vecinos pero cuyos gobiernos nacionales sí lo son y paradiplomacia global que designa los contactos que mantienen los gobiernos no centrales con centros comerciales, industriales, culturales o con los diversos departamentos de los gobiernos nacionales de otros continentes.

En torno a la perspectiva metodológica sobre la cual se construye nuestro estudio, optamos por un diseño preponderantemente cualitativo. Como correlato, esta investigación se apoya tanto en fuentes primarias como secundarias. Respecto a las primeras se tendrán en consideración: declaraciones de altos funcionarios provinciales, comunicados e informes de prensa de la provincia de Santa Fe, documentos de trabajo de la provincia y el Plan Estratégico Provincial. Amén de ello se efectuaron dos entrevistas semi estructuradas a funcionarios del gobierno provincial que desempeñaron sus funciones durante el periodo de referencia del trabajo. En tanto, entre las segundas, se emplearan libros y publicaciones, entre 
ellos una serie de informes elaborados por el Centro Argentino de Relaciones Internacionales (CARI) en el marco del programa "Provincias y relaciones Internacionales", así como también artículos de prensa: diarios La Capital, Uno, entre otros.

Dicho esto, en un primer apartado del trabajo daremos cuenta del contexto en el marco del cual se produce el acercamiento entre la provincia y los actores del golfo, así como también de los objetivos que ha perseguido el mismo. En tanto, en un segundo apartado, atenderemos a las acciones implementadas con vistas a propiciar tal aproximación y, a su vez, a los resultados de la misma.

Génesis, contexto y objetivos del acercamiento de la provincia de Santa Fe a Kuwait e EAU

En lo que atañe específicamente a la República Argentina, allí el manejo de las relaciones exteriores y la definición de la política exterior es potestad del Poder Ejecutivo Nacional. Además, le incumbe al Congreso Nacional reglamentar el comercio con otros países (artículo 75 inc. 13 de la Constitución Nacional Argentina) y fijar los derechos de importación y exportación (artículo 75 inc. 1). No obstante, según el artículo 124 de la Constitución Nacional:

Las provincias podrán crear regiones para el desarrollo económico y social y establecer órganos con facultades para el cumplimiento de sus fines y podrán también celebrar convenios internacionales en tanto no sean incompatibles con la política exterior de la Nación y no afecten las facultades delegadas al Gobierno federal o el crédito público de la Nación, con conocimiento del Congreso Nacional.

La relevancia de este artículo, que introduce la reforma constitucional de 1994, está dada a raíz de que el mismo reconoce no sólo la capacidad de las provincias de conformar regiones sino también su potestad de realizar gestión internacional ${ }^{2}$.

Al respecto, Zubelzú; Colacrai (2004) mencionan que, en un primer momento, la actuación internacional de las provincias argentinas, que como ya mencionamos comenzó a cobrar vigor en la década del noventa, se circunscribió al estrechamiento de lazos con países limítrofes, lo que las autoras catalogan como la modalidad de vinculación externa más tradicional y antigua practicada por los países. Si bien, paulatinamente, la gama de actividades y de actores con los que se sostenían lazos se fue ampliando conforme con la estrategia y los objetivos en materia de inserción internacional de cada una de las unidades provinciales.

En lo que respecta específicamente a la provincia de Santa Fe, del análisis de sus principales socios comerciales ${ }^{3}$, los convenios por ésta firmados en las más diversas materias ${ }^{4}$, las visitas diplomáticas recibidas ${ }^{5}$ e, incluso, de la información recabada de manos de funcionarios gubernamentales se desprende que durante el periodo que abarca el trabajo el ente provincial estrechó sus lazos con múltiples actores. Si bien es cierto que entre los mismos tuvieron un lugar de privilegio entidades sudamericanas y europeas. Entre ellos gobiernos de distintos niveles de países vecinos, como es el caso de Brasil, y también de países europeos, con

\section{Ahora bien, un problema que} presenta este artículo reside en que los límites del accionar provincial aparecen mencionados genéricamente y de forma negativa. Es decir, la redacción de esta norma no conlleva un nivel de profundidad que permita especificar en detalle las materias ya sea habilitadas 0 vedadas al accionar provincial.

Siles (2014) señala que la imprecisión del reconocimiento constitucional sobre el accionar externo de las provincias ha provocado dificultades a la hora de determinar la frontera potencial del accionar provincial lo que resulta fundamental por la posible responsabilidad internacional que podría derivarse del mismo.

En relación a lo expuesto se ha desencadenado un arduo debate que gira en torno a si el artículo 124 debería ser reglamentado -o no- $y$, en el primer caso, a quien correspondería dicha reglamentación. Al respecto, existen postura encontradas entre juristas que conciben que esta tarea debería recaer ya sea en la órbita del Congreso o de las mismas provincias.

Lo cierto es que la necesidad de la reglamentación se anclaría, entre otros motivos, en evitar cualquier conflicto de orden práctico que pudiese suscitarse entre el Estado federal y los entes provinciales. Un caso paradigmático en este sentido se encuentra en relación a la represa de Corpus Christi.

Como correlato de lo hasta aquí expuesto cobra especial relevancia una reflexión de Vigvani (2006) quien menciona que dado que la paradiplomacia ingresa en un campo donde existen formas difusas de actuación y los límites legales no son precisos, con vistas a evitar cualquier espacio de conflicto resulta imperativo esclarecer las atribuciones y parámetro jurídico-legales que envuelven el accionar externo de los actores subnacionales.

3. Estadísticas y datos relativos al comercio exterior de la provincia de Santa Fe pueden ser consultados en la página oficial del Instituto Provincial de Estadística y Censos (IPEC).

4. Los convenios firmados por la provincia durante el periodo que abarca el trabajo pueden ser consultados en:< https://www.santafe.gov.ar/conv_int/>

5. SECRETARÍA DE RELACIONES INTERNACIONALES E INTEGRACIÓN. La internacionalización de la Provincia de Santa Fe. Estrategias y avances 20112015, 2016. 
6. Entrevista efectuada a Anabella Busso, quien fuera subsecretaria de la Agencia de Cooperación Internacional para el Desarrollo de la provincia de Santa Fe entre 2006 y 2008, Rosario, 04 nov. 2017

7. En relación con lo hasta aquí expuesto cabe aclarar que cada una de las provincias argentinas ha privilegiado sus vínculos con distintos actores, ya sea regionales o internacionales, así como también diversas áreas de cooperación. Al respecto, Busso destaca que durante su gestión Misiones ya contaba con una amplia trayectoria a la hora de

impulsar el turismo. En este sentido, agrega que su estrategia subnacional de inserción se relacionaba directamente con el fomento del turismo internacional. Mientras tanto, de acuerdo con los dichos de la funcionaria, las provincias cuyanas tenían una agenda en un 95\% centrada en la contraparte chilena. En tanto, las provincias pertenecientes a la Patagonia impulsaban no sólo el turismo sino también la marca Patagonia, lo que implicaba un importante esfuerzo en pos del trabajo conjunto. los cuales Argentina posee una larga historia compartida como fruto del proceso migratorio que tomó lugar entre finales del siglo XIX y principios del siglo XX.

Al respecto, Anabella Busso ${ }^{6}$, quien fuera Subsecretaria de la Agencia de Cooperación Internacional para el Desarrollo de la provincia, menciona que durante su gestión Santa Fe mantenía importantes lazos con Italia en una instancia en la que la cooperación técnica italiana ponía a disposición líneas de trabajo para PYMES y para el desarrollo agrícola de pequeñas comunidades. A su vez, da cuentas de la firma de acuerdos de hermanamiento con distintas ciudades particularmente de la región de Piamonte. A lo que agrega que la cooperación con España era importante ya al inicio de su gestión, si bien esta se fortaleció a lo largo de la misma permitiendo la firma de convenios con la ciudad de Barcelona y diversas entidades del gobierno Vasco. Con estos actores, agrega, se superó aquella que hasta el momento había sido la temática central de la cooperación, el fortalecimiento institucional, para comenzarse a trabajar en materia de salud'. Busso también recuerda que durante la etapa final de su gestión, que culminó en 2008, la provincia buscó acercarse a socios no tradicionales con vistas a la persecución de objetivos económico-financieros. De esta forma, se iniciaba una etapa de diversificación de las relaciones exteriores en la que se apostaba a estrechar lazos con países emergentes como es el caso de la República Popular China y Rusia. Cabe agregar que, la funcionaria da cuentas de que en ese momento se trabajó con una perspectiva subregional que se plasmó en la participación en diversas misiones conjuntas con la Región Centro que, asimismo, en algunos casos fueron acciones coordinadas con la nación.

Ahora bien, en lo referente a los lazos que estrecha la provincia de Santa Fe con EAU y Kuwait, que pueden ser referidos como un claro ejemplo de paradiplomacia global en tanto se suscitan entre actores pertenecientes a distintos continentes, vale mencionar que los mismos se inscriben en el marco de la estrategia de diversificación de relaciones a la que apostaron las autoridades provinciales.

$\mathrm{Al}$ respecto de estas relaciones es menester mencionar que, como ya adelantamos, las mismas comenzaron a gestarse durante la administración del gobernador Hermes Binner (2007-2011), para continuar cimentándose durante las gestiones de sus sucesores y copartidarios Antonio Bonfatti $(2011,2015)$ y Miguel Lifschitz (2015). De esta forma, pese a que Zubelzú (2004) menciona que la acción externa de las provincias no escapa a los vaivenes propios de los cambios políticos surgidos a raíz de los procesos electorales tanto vinculados a la alternancia político partidaria como a recambios de las máximas autoridades provinciales dentro de una misma pertenencia partidaria, en este caso se percibe una continuidad en el esfuerzo de las autoridades provinciales en pos de la profundización de estos lazos.

Ahora, es importante mencionar que, por un lado la provincia de Santa Fe se ha inclinado por tener una presencia directa en los países del golfo. Por otro, aunque sus acciones no siempre han sido coordinadas con el gobierno nacional, estas se han inscripto en un marco caracterizado por la profundización de los vínculos entre los gobiernos nacionales de los tres países en cuestión. 
De hecho, el acercamiento entre la provincia de Santa Fe, Kuwait y EAU se produjo en un contexto signado por la aproximación de Argentina a las monarquías del golfo que no tiene antecedentes en la historia de los vínculos bilaterales (FABANI, 2015). Efectuamos esta afirmación ya que durante los gobiernos de Fernández (2007-2015) se multiplicaron las visitas oficiales, las misiones comerciales, los encuentros de negocios y los acuerdos firmados no sólo entre Argentina, EAU y Kuwait sino también entre la primera, Arabia Saudita y Qatar ${ }^{8}$.

En esta misma dirección también se avanzó en la apertura de misiones diplomáticas. Al respecto, en lo que atañe al periodo de referencia, en 2008 EAU abrió su embajada en Buenos Aires. Mientras que, en 2013, Qatar y Argentina designaron sus primeros embajadores. De esta forma, en la actualidad Argentina cuenta con embajadas en cuatro de las seis monarquías del golfo, puesto que en los casos de Omán y Bahréin existe una representación concurrente en el reino saudita 9 .

En tanto, en este ámbito se evidencia una línea de continuidad entre los gobiernos de Fernández y el del actual presidente Macri, quien desde su llegada al poder se ha preocupado por sostener estos vínculos.

Durante los gobiernos del FPV el modelo de desarrollo condicionó la estrategia de inserción internacional y la política exterior (BUSSO; FABANI, 2015, p. 24). Respecto a este último, se impuso el "neodesarrollismo" que se caracteriza por un conjunto de políticas públicas que tienen por fin eliminar o compensar, mediante la intervención del Estado, las fallas del mercado, desempeñando aquel un rol de promotor de las actividades productivas. En esta misma dirección, durante los gobiernos del Frente las variables económicas adquirieron una importante gravitación en lo referente a la vinculación de la Argentina con el mundo. Esto se hace evidente si se atiende a la búsqueda de estas administraciones de que los vínculos con el exterior se tradujesen en nuevas posibilidades de negocios con distintas regiones, en una diversificación de las exportaciones y, asimismo, en nuevas inversiones.

En este marco tomó lugar el acercamiento de la Argentina a las monarquías del golfo. De hecho, al repasar la agenda de las visitas, encuentros y contactos de alto nivel entre representantes del país y los Estados del golfo durante los gobiernos de Cristina Fernández se hace patente que los mismos tuvieron entre sus fines últimos hacer negocios e impulsar inversiones. Esto en línea con una serie de "objetivos estratégicos" de la gestión que apuntaron a: "el crecimiento y la diversificación de nuestras ventas al mundo; la creación de una sólida cultura exportadora en el seno del sector productivo nacional" (SECRETARÍA DE COMUNICACIÓN PÚBLICA, 2011). En esta dirección, en 2011 el canciller Timerman señalaba:

\footnotetext{
El crecimiento de nuestras ventas al mundo reconoce como uno de sus pilares a la estrategia de diversificación de nuestra oferta exportable y a una política comercial que prioriza la apertura de nuevos mercados para las exportaciones argentinas, logrando posicionar la producción nacional en mercados menos tradicionales como África - particularmente la región del Magreb-, Medio Oriente, la India y el Sudeste Asiático, entre otros (SECRETARÍA DE COMUNICACIÓN PÚBLICA, 2011).
}

En tanto, en lo referente a los países del golfo, conforme con un comunicado de prensa de la Cancillería Argentina del 14 de febrero de 2014,
8. Para mayor información ver: FABANI, Ornela. El devenir de las relaciones entre Argentina, Emiratos Árabes Unidos y Qatar durante los gobiernos de Cristina Fernández (2007-2015): vínculos modestos en evolución, Revista de Estudios Internacionales Mediterráneos, n. 21, 2016. Y FABANI Ornela. Un acercamiento a socios no tradicionales: la evolución del vínculo entre la Argentina y las monarquías del golfo durante las administraciones de Cristina Fernández (2007-2015), Universidade Autónoma de Lisboa, v. 6, n. 2, 2015.

9. Vale aclarar que el país abrió su embajada en Arabia Saudita en 1964, en EAU en 1983 y en Kuwait en 1993. 
el gobierno nacional juzgaba que estos constituían destinos estratégicos por diversas razones. "Entre ellas, su papel protagónico en los mercados de gas y petróleo y sus elevados superávits de cuenta corriente que les permiten acumular excedentes para destinar a consumo e inversión" (MINISTERIO DE RELACIONES EXTERIORES,2014).

Como se evidencia en virtud de lo hasta aquí expuesto, los intereses económico-comerciales han tenido un rol central a la hora de traccionar los vínculos político-diplomáticos entre el gobierno nacional argentino y los países del golfo no sólo durante los gobiernos de Fernández sino también en lo que va de la gestión del presidente Macri, quien pese a proponer un modelo de desarrollo económico alternativo, que encuentra marcadas diferencias con aquel que abrazó la gestión precedente, persigue como un objetivo central la recepción de inversión extranjera.

Ahora bien, es pertinente mencionar que en lo que respecta al intercambio comercial con los países del golfo más allá del interés de los gobiernos del Frente para la Victoria de impulsar el mismo éste ha sido bajo.

Tabla 1- Exportaciones totales de Argentina - Valores en miles de U\$S

\begin{tabular}{c|c|c|c|c|c|c|c|c|c|c}
\hline País & $\mathbf{2 0 0 7}$ & $\mathbf{2 0 0 8}$ & $\mathbf{2 0 0 9}$ & $\mathbf{2 0 1 0}$ & $\mathbf{2 0 1 1}$ & $\mathbf{2 0 1 2}$ & $\mathbf{2 0 1 3}$ & $\mathbf{2 0 1 4}$ & $\mathbf{2 0 1 5}$ & $\mathbf{2 0 1 6}$ \\
\hline Arabia Saudita & 372486 & 445415 & 312114 & 309258 & 626298 & 789036 & 1162995 & 811893 & 421378 & 664457 \\
\hline Bahréin & 3679 & 5688 & 3165 & 3349 & 15818 & 19705 & 4861 & 4183 & 2794 & 3953 \\
\hline EAU & 191225 & 356852 & 237340 & 272193 & 337236 & 280624 & 256368 & 200136 & 173734 & 240036 \\
\hline Kuwait & 39820 & 30227 & 16283 & 32313 & 25362 & 31342 & 53694 & 51840 & 33858 & 21977 \\
\hline Omán & 25414 & 57383 & 45077 & 39695 & 59003 & 39000 & 34301 & 28702 & 29156 & 42976 \\
\hline Qatar & 15338 & 16142 & 21619 & 5105 & 13228 & 8932 & 5223 & 12193 & 11548 & 8171 \\
\hline
\end{tabular}

Fuente: SICOEX ALADI

Tabla 2- Importaciones totales de Argentina - Valores en miles de U\$S

\begin{tabular}{c|c|c|c|c|c|c|c|c|c|c}
\hline País & $\mathbf{2 0 0 7}$ & $\mathbf{2 0 0 8}$ & $\mathbf{2 0 0 9}$ & $\mathbf{2 0 1 0}$ & $\mathbf{2 0 1 1}$ & $\mathbf{2 0 1 2}$ & $\mathbf{2 0 1 3}$ & $\mathbf{2 0 1 4}$ & $\mathbf{2 0 1 5}$ & $\mathbf{2 0 1 6}$ \\
\hline Arabia Saudita & 23616 & 26997 & 1993 & 28874 & 33763 & 75269 & 19660 & 62597 & 176506 & 245946 \\
\hline Bahréin & 1435 & - & - & 17328 & - & 5044 & 6841 & 990 & 276 & 445 \\
\hline EAU & 18021 & 5007 & 2819 & 14829 & 48117 & 32942 & 49494 & 29741 & 40070 & 70894 \\
\hline Kuwait & 19641 & 8 & 3 & 1968 & 7170 & 30746 & - & 8085 & 1836 & 14818 \\
\hline Omán & - & 3 & 84 & 5104 & 24295 & 654 & 1445 & 3940 & 22255 & 45597 \\
\hline Qatar & 24569 & 5086 & 189 & 75284 & 290873 & 448592 & 1060505 & 828767 & 172567 & 276158 \\
\hline
\end{tabular}

Fuente: SICOEX ALADI

Cabe agregar que, entre los seis actores del golfo Arabia Saudita se presenta como el principal socio del gobierno nacional, seguido en segundo lugar por EAU. En sintonía con lo que ocurre en el plano nacional, y siguiendo la clasificación de De Marsilio, también han sido factores económicos aquellos que han impulsado el acercamiento de la provincia de Santa Fe a EAU y Kuwait.

Lo cual se explica si tenemos en cuenta que las seis monarquías del golfo en conjunto poseen alrededor del $30 \%$ de las reservas probadas de crudo a nivel global. Aún más, estos Estados detentan de forma conjunta el $23 \%$ de las reservas probadas de gas a nivel mundial (MELTZER, 
HULTMAN, LANGLEY, 2014: 18). Al respecto, EAU se posiciona como el séptimo país del mundo por el tamaño de sus reservas de petróleo, 97.800 millones de barriles. Además, cuenta con importantes reservas de gas natural, 215.000 millones de pies cúbicos, también las séptimas a nivel internacional (OFICINA ECONÓMICA Y COMERCIAL DE ESPANA EN DUBAI, 2014, p.15). Mientras Kuwait se ubica noveno en el ranking en función del tamaño de sus reservas de crudo (CIA, 2017).

Ahora, a partir de la importancia de estos recursos para las economías de los citados países éstos han obtenido sendos beneficios económicos que les han permitido transitar una etapa de crecimiento exponencial durante las últimas décadas. De allí el interés de la provincia de Santa Fe en acercarse a estos países árabes, que no sólo cuentan con millonarios fondos soberanos sino que también se presentan como socios potenciales en virtud de su necesidad de asegurarse el acceso a alimentos y tecnología.

En este sentido, conforme con el Sovereign Wealth Fund Institute (2016), el fondo soberano de Abu Dhabi es el tercero en relevancia a nivel internacional seguido, en quinto lugar, por el vehículo de inversión de Kuwait.

Teniendo en consideración lo expuesto, un informe elaborado por la gestión Binner da cuentas de los principales objetivos de las misiones institucionales así como también comerciales que tuvieron por destino Kuwait y EAU. Entre ellos se cita la obtención de financiamiento para proyectos provinciales tales como el sistema de acueductos, parques y áreas industriales, el desarrollo de zonas francas y puertos sobre el río Paraná. Además, se menciona la búsqueda de inversores que podrían arribar al país por medio de la creación de joint ventures. Esto amen de señalarse la necesidad fortalecer el intercambio comercial entre las partes (GOBIERNO DE SANTA FE, 2011).

En lo que respecta a este último punto, Kuwait y EAU no aparecen entre los Estados árabes a los que la provincia más exporta en Medio Oriente, que coinciden con países ubicados en el norte de África, ni tampoco entre los mejores clientes entre las monarquías del golfo, entre los que se encuentra Arabia Saudita (IPEC, 2017). De cualquier forma, un documento de trabajo que repasa lo actuado por la gestión Binner estipula que la gestión salió al mundo concentrándose en pocos destinos y pensando en aquellos países con los que se pudiese tener un marco de construcción conjunta de mediano y largo plazo. Dicho lo cual destaca que Kuwait y EAU fueron concebidos como hubs comerciales que podían convertirse en una puerta de vinculación con distintos mercado en Asia y Medio Oriente (GOBIERNO DE SANTA FE, 2011).

En esta misma dirección el entonces ministro de economía santafesino, Fascendini, señalaba:

A pesar de que las exportaciones a EAU y a los países árabes no son hasta el
momento significativas en cuanto a sus volúmenes [...] Vislumbramos que era
fundamental establecerse en la región ya que Dubai se convirtió en un centro
comercial desde donde se opera a diversos países; no sólo del mundo árabe sino
a India, China, Indonesia y resto del Sudoeste asiático, como así también existen
conexiones a países de África y el Este de Europa (INFOCAMPO, 2013).

A lo que agregaba que el gobierno provincial, en su búsqueda de apoyar a las medianas y grandes empresas a encontrar nuevos mercados, se 
venía concentrando en los países que estaban mostrando mayores tasas de crecimiento, tanto en lo económico como en lo poblacional. En esta línea el ministro daba cuenta del esfuerzo que se estaba efectuando en pos de profundizar las relaciones comerciales con los países emergentes. Mientras que en lo referente a las potencialidades de estos mercados Fascendini subrayaba que los mismos estaban requiriendo alimentos no sólo en mayores cantidades sino con mayor valor agregado; una demanda a la que se ha juzgado que la provincia puede dar respuesta (INFOCAMPO, 2013).

Ahora, vale mencionar que si bien tanto la nación como la provincia han salido a buscar nuevos mercados, inversiones y, en definitiva, han apostado por diversificar sus socios, esta última ha protagonizado tanto acciones coordinadas como paralelas con el gobierno nacional. En torno a estas últimas en cierta medida estas se explican considerando que durante los gobiernos del FPV las relaciones entre el actor nacional y aquel subnacional fueron tensas en una instancia en la que estos no compartieron la misma orientación política. A modo de ejemplo, pese a las reiteradas solicitudes del gobernador Bonfatti la presidente Fernández nunca le brindó una audiencia a lo largo de toda su gestión. Entre los factores que suscitaron fricciones entre ambos actores podemos mencionar el reclamo del gobernador por la deuda que mantenía el Estado nacional con la provincia, la problemática de la seguridad y las acusaciones cruzadas en torno al flagelo del narcotráfico. Aún más, otro factor que dificultó el vínculo entre las partes fue precisamente la demora por parte del gobierno nacional en la aprobación de un crédito que, como veremos a continuación, suscribió la provincia con el Fondo Kuwaití para el Desarrollo Económico y Social.

Las acciones en las que se plasma el acercamiento de la provincia de Santa Fe a EAU y Kuwait y sus resultados

Tal como adelantamos, la gestión Binner comenzó a trabajar con vistas a promover sus vínculos con los países árabes a poco de su llegada al poder. De esta forma, ya en diciembre de 2008, una delegación de embajadores árabes acreditados en la Argentina visitaba la Casa de Santa Fe, en la Capital Federal. Si bien en dicha oportunidad los representantes de Kuwait y EAU no se encontraron entre los presentes puede pensarse dicho encuentro como un antecedente al posterior acercamiento a estos actores del mundo árabe. En el marco de la citada reunión el gobernador santafecino manifestó que la historia argentina se encontraba atravesada por la inmigración a la par que destacó como una característica del país el alto grado de integración entre las diversas comunidades que lo conforman. Esto para luego mencionar la necesidad de trabajar todos juntos para que Argentina tenga un mejor porvenir, en lo económico y en lo social y expresar su deseo de que el diálogo fructifique en relaciones comerciales. Asimismo, al cierre de este encuentro adelantó que los embajadores árabes recibirían una invitación formal para visitar Santa $\mathrm{Fe}$ (GOBIERNO DE SANTA FE, 2008).

En virtud de dicho compromiso, en marzo de 2009, una delegación integrada por los embajadores de la República Árabe de Siria, la Repúbli- 
ca del Líbano, el Reino de Arabia Saudita, la Liga de Estados Árabes, así como también del Estado de Kuwait y EAU arribó a Santa Fe. El objetivo de este encuentro fue mostrar a los representantes árabes las potencialidades de la provincia; con este fin los funcionarios de los mencionados países no sólo recorrieron el territorio santafecino sino también empresas de la zona.

Mientras tanto, en el mes de julio, el embajador de Kuwait en Argentina devolvió el convite con un almuerzo al cual fue invitado el gobernador de Santa Fe junto a un grupo de embajadores árabes. Este encuentro otorgó continuidad a los contactos entre ambas partes y se dedicó a abordar cuestiones tales como: las posibilidades para el desarrollo de joint ventures y para la realización de inversiones en actividades productivas; el desarrollo del sistema logístico puerto de Santa Fe-puerto de los países árabes; la participación en ferias internacionales y misiones comerciales, los intercambios técnicos y consorcios de exportación por sectores. Además, se analizaron las barreras que limitan la integración y las posibles soluciones mediante aspectos vinculados con la legislación, el desarrollo del sistema financiero, la presencia de bancos árabes en Santa Fe, y los instrumentos financieros de apoyo a la provincia. En tanto, la inversión en infraestructura pública y la promoción de intercambios científicos tecnológicos fueron otros temas abordados.

Tiempo después, ya en el mes de junio de 2010, tuvo lugar la primera misión institucional organizada por el gobierno de Binner a Kuwait y EAU. La misma fue encabezada por el gobernador quien fue acompañado por el ministro de Economía, Ángel Sciara y el ministro de Producción, Juan José Bertero. En tanto, la agenda de la comitiva oficial contempló reuniones con autoridades de los Poderes Ejecutivo y Legislativo, agencias de gobierno y cámaras empresarias, con el objetivo de establecer contactos institucionales, comerciales y científicos.

En Kuwait tuvieron lugar reuniones con el emir, el primer ministro, el ministro de Finanzas Comercio e Industria y el presidente del parlamento con el fin de iniciar contactos que permitiesen evaluar las alternativas de financiamiento de obras públicas y para el sector privado. Asimismo, se concretó un encuentro con el gobernador de Al Ahmadi, la provincia más importante del Emirato en términos productivos, para acordar la firma de un acuerdo de fraternidad que tiempo después se rubricaría con la provincia de Santa Fe. Mientras que, a su vez, se organizó una reunión con miembros de la Cámara de Comercio e Industria de Kuwait y se efectuó una visita al Instituto de Investigación Científica. Esto sin mencionar que el gobernador se reunió con autoridades del Fondo Kuwaití para el Desarrollo Económico Árabe ${ }^{10}$.

Este último emerge como una agencia estatal que tiene por fin brindar asistencia financiera y técnica a los países en desarrollo. De esta forma, el mismo financia proyectos de agricultura, transporte, energía, industria, así como también vinculados a la gestión del ciclo del agua. En esta línea, en la reunión que tuvo lugar con las autoridades de Santa Fe estas manifestaron su interés de avanzar en la concreción de una operación de financiamiento destinada a la construcción de un acueducto en el norte de la provincia. Básicamente en dicha instancia se presentó ante el
10. El Fondo Kuwaití para el Desarrollo Económico Árabe es una entidad surgida en 1961 que desde 2003 depende del Ministerio de Asuntos Exteriores y del Ministerio de Hacienda. A partir de su desempeño el fondo es concebido como un instrumento de la política y acción exterior de Kuwait tanto en el ámbito de la ayuda al desarrollo como de la ayuda humanitaria. Este punto es importante ya que esto lo distingue del Fondo Soberano kuwaití, la Kuwait Investment Authority, que depende del Ministerio de Finanzas y tiene por fin rentabilizar, atendiendo a criterios de prudencia y riesgo limitado, los excedentes que genera la renta del petróleo. 
fondo kuwaití una solicitud de financiamiento para el proyecto "Sistema de Acueducto Noreste 2" o "Acueducto Reconquista".

Como corolario de esta visita, en una entrevista que brindó el ministro de la Producción como miembro de la comitiva oficial este señaló:

Acá venimos a buscar el financiamiento para obras públicas y también el apoyo para financiar algunas iniciativas privadas. Queremos interesarlos en la realización de inversiones en la estructura productiva de la provincia [...] Estamos hablando de gobiernos que poseen recursos líquidos y ansiedad de inversiones productivas y, a la par, tienen necesidades concretas a las que podríamos darle respuestas. Me refiero a que importan la mayoría de los bienes de consumo en todos los órdenes y es allí donde sentimos que podemos abrirles un campo de inversión muy importante (LA CAPITAL, 2010).

En este sentido, cabe destacar que las monarquías del golfo no detentan una ventaja comparativa en la producción de alimentos sino que, por el contrario, su seguridad alimentaria depende, en gran medida, de sus importaciones. Tal es así que, en virtud de las particulares características de su clima y sus suelos éstos países se ven ante la necesidad de importar entre un $80 \%$ y un $90 \%$ de los alimentos que consumen (BAILEY; WILLOUGHBY, 2013). De hecho, los Estados del golfo no sólo deben afrontar temperaturas máximas extremas, lo que limita el rendimiento de muchos cultivos, sino que en dichos países las precipitaciones resultan insuficientes para la producción de algunos cereales como es el caso del trigo. Aún más, sus recursos renovables de agua fresca se encuentran entre los más bajos del mundo. Esto sin mencionar que sus suelos son frágiles y que el $95 \%$ de la tierra en la península arábiga se encuentra sujeta a alguna forma de desertificación (BAILEY; WILLOUGHBY, 2013). Tal es así que en Kuwait sólo $0,8 \%$ de la tierra es cultivable (INSTITUTO DE FOMENTO DE MURCIA, 2014).

Dicho esto, tal como mencionase el ministro, Santa Fe se acercó a países que cuentan con vastos recursos en un contexto marcado por la situación acuciante de las arcas provinciales frente a la cual las autoridades provinciales reconocían la necesidad de recibir "un shock de recursos económicos y de generación de infraestructura" (LA CAPITAL, 2010). En efecto, los gobiernos que se han sucedido en el poder durante el periodo de referencia han manifestado que la búsqueda de financiamiento externo responde a que la ejecución de obras públicas involucra montos de inversión que exceden la capacidad financiera del gobierno provincial (ESPERANZA DÍA POR DÍA, 2012; UNO SANTA FE, 2016), agregando que los gastos corrientes consumen cada vez una mayor proporción del presupuesto (PAUSA, 2014). Esto en un escenario en el que además la provincia ha mantenido una prolongada disputa con el gobierno nacional al que le ha reclamado una deuda millonaria en concepto de fondos de coparticipación.

Retomando las negociaciones iniciadas en el mes de junio, en julio de 2010 el gobernador y el ministro de Economía de la provincia se reunieron con el director general del Fondo de Kuwait para el Desarrollo Económico Árabe, Abdulwahab Al-Bader, quien arribó al país como parte de la comitiva que acompañó al primer ministro, jeque Nasser Almoham- 
med Alsabah, en su gira por Latinoamérica. El objetivo del encuentro residió en avanzar con las tratativas en pos de recibir financiamiento árabe para la construcción del ya referido acueducto proyectado en el norte de la provincia.

Las autoridades de la provincia de Santa Fe, a diferencia de otros gobiernos provinciales, no participaron de la gira que emprendió la presidente Fernández por Medio Oriente en enero de 2011. Esta situación expone no sólo el accionar paralelo que en muchas oportunidades han desempeñado ambos actores en la región del golfo sino también la tirantez en el vínculo entre el gobierno provincial y el nacional que, como contrapartida al grupo de funcionarios que acompañó a la comitiva presidencial, no compartía la misma pertenencia partidaria que el gobierno nacional. No obstante, la provincia formó parte de una delegación de la Región Centro que asistió a la Feria Gulfood en el mes de febrero. En dicho caso la presencia en el pabellón argentino fue coordinada y contó con el patrocinio del Consejo Federal de Inversiones $(\mathrm{CFI})^{11}$ y la Fundación Exportar. La participación en esta feria se transforma entonces en otra acción que pone evidencia el acercamiento entre las partes, si bien en este caso la provincia no actuó de forma independiente sino como parte de la Región Centro.

Esta última se institucionalizó en 1998 a partir de la suscripción de un Tratado interprovincial de Integración Regional entre los gobiernos de las provincias de Santa Fe y Córdoba; una iniciativa a la cual un año después se sumó la provincia de Entre Ríos. Al respecto, este actor surgió con vistas a poder afrontar de forma conjunta los procesos de globalización y regionalismo en ciernes, en tanto su conformación también favoreció la posibilidad de articular demandas y posturas frente al gobierno nacional. Aún más, el trabajo conjunto entre las tres unidades provinciales, que emerge como un ejemplo de cooperación intrafederativa, tiene por fin el "conformar instrumentos de integración regional a efectos de garantizar la vigencia plena del federalismo, estableciendo los lineamientos de una política común de desarrollo, que abarque aspectos económicos, sociales, culturales y educativos, abordando las problemáticas y las potencialidades del todo" (GOBIERNO DE SANTA FE, 2017).

De esta forma, las regiones emergen como otro actor subnacional que, junto a las provincias, ha logrado tener presencia en el campo internacional. En el caso de la Argentina, como ya hemos visto, el artículo 124 de la Constitución Nacional habilita su conformación.

Cabe destacar que la promoción comercial es una de las actividades más desarrolladas por las regiones en la Argentina. Aún más, tradicionalmente la Región Centro ha sido una de las más activas a la hora de implementar estas acciones de forma conjunta y coordinada, entre las cuales la participación en ferias internacionales es sólo un ejemplo (IGLESIAS, 2008).

Culminada la feria en EAU las autoridades santafecinas continuaron su viaje hacia Kuwait protagonizado la segunda misión institucional en tan sólo siete meses. Allí la delegación encabezada por el ministro de la Producción se reunió con miembros de la Cámara de Comercio e Industria de Kuwait a quienes se invitó a participar de distintas ferias y eventos que tendrían lugar en el escenario provincial. Además, en dicha oportuni-
11. El Consejo es una entidad donde se encuentran representadas las diversas provincias que apunta a promover el desarrollo armónico del país y el bienestar social actuando como una macro coordinadora entre las provincias y entre ellas y distintas agencias nacionales de promoción. 
dad se entregó un Documento de Fraternidad firmado por el gobernador Hermes Binner, cuya gestión se había iniciado con la máxima autoridad de la provincia de Al-Ahmadi en 2010 durante la misión de la provincia de Santa Fe. La firma de este acuerdo se convirtió entonces en otro resultado de la paradiplomacia provincial. Al respecto, dicho documento prevé trabajar en pos de: la preservación y restauración del patrimonio nacional, la protección al medioambiente, la promoción y el desarrollo del comercio exterior y la cooperación económica, la planificación arquitectónica y el desarrollo urbano, el intercambio cultural y deportivo, el fomento de la cooperación científica y tecnológica. Finalmente, también existió un encuentro con autoridades del Fondo Kuwaití para el Desarrollo Económico Árabe que confirmaron su disposición al otorgamiento del préstamo para la construcción del acueducto.

En función de la progresiva profundización de los lazos con los actores árabes, de regreso de Medio Oriente el ministro de la Producción organizó un encuentro en la Bolsa de Comercio de Rosario con distintas instituciones y actores ligados al sector productivo de la provincia para realizar una presentación de las potencialidades y oportunidades del mercado árabe en la cual se puso especial énfasis en las bondades de EAU y el Estado de Kuwait.

Mientras tanto, en abril de 2011, Binner recibió al embajador de Kuwait en Argentina en la ciudad de Rosario. Este nuevo encuentro tuvo por fin dar continuidad al vínculo entablado por Santa Fe con el país árabe y respondió a la invitación cursada por la provincia de organizar una misión empresarial que participase de distintas ferias y eventos que tendrían lugar en la misma. En tanto, como parte de su visita, el diplomático árabe concretó encuentros con diversos actores donde volvió a insistir en las oportunidades que presentaba el mercado del mundo árabe.

Ahora bien, en lo que respecta al intercambio comercial entre las partes hemos de referir que, en línea con lo que ocurre en el plano nacional, a pesar de las acciones emprendidas con el objetivo de impulsar el mismo éste ha resultado no sólo magro sino también fluctuante. De cualquier forma, al efectuarse una lectura comparativa de las tres gestiones bajo análisis claramente la administración Binner se erige como aquella que ha alcanzado los mejores resultados si tenemos en cuenta que el pico máximo de exportaciones a Kuwait durante el periodo bajo estudio se logró en 2008, U\$ $\$$ 6.134.855. En tanto las mayores exportaciones a EAU tuvieron lugar en 2010 ascendiendo a U\$\$ 124.709.967 (IPEC, 2017).

En otro orden, a fines de 2011, fruto de las elecciones del mes de julio, se produjo un recambio de autoridades en la provincia de Santa Fe. $\mathrm{Si}$ bien es importante mencionar que tal situación no supuso un cambio del partido en el gobierno, en tanto los comicios se cerraron con una nueva victoria del socialismo. Se alude a esta situación con vistas a destacar que, pese a la asunción de una nueva administración, esto no supuso un quiebre en el vínculo con los gobierno de Kuwait y EAU sino que, por el contrario, las relaciones con estos países se mantuvieron a la orden del día. No obstante, resulta necesario mencionar que durante la gestión de Bonfatti las relaciones con EAU parecen haber cobrado preeminencia por sobre los lazos con Kuwait. Esto a pesar de que fue esta administración la 
que concretó la firma del acuerdo con el Fondo de Kuwait para el Desarrollo Económico Árabe.

Tabla 3-Valor de las exportaciones con origen en la provincia de Santa Fe $(2007-2016)^{12}$

\begin{tabular}{c|c|c}
\hline Año & EAU & Kuwait \\
\hline 2007 & 18.547 .920 & 4.155 .273 \\
\hline 2008 & 72.881 .144 & 6.134 .855 \\
\hline 2009 & 66.659 .746 & 2.944 .725 \\
\hline 2010 & 124.709 .967 & 4.626 .239 \\
\hline 2011 & 95.425 .815 & 4.726 .285 \\
\hline 2012 & 34.800 .908 & 3.123 .461 \\
\hline 2013 & 44.411 .481 & 4.787 .786 \\
\hline 2014 & 23.598 .586 & 3.803 .433 \\
\hline 2015 & 11.944 .145 & 2.871 .760 \\
\hline 2016 & 29.946 .142 & 1.769 .205 \\
\hline
\end{tabular}

Fuente: Elaboración propia en base a datos del IPEC (2016)

Dicho esto, entre las acciones formales emprendidas por la administración Bonfatti que tuvieron por destinatarios a los países del golfo en mayo de 2012 el gobernador participó de una misión comercial e institucional, gestionada por el CFI, que tuvo por destino Arabia Saudita, Kuwait y EAU. En torno a los países que aquí nos interesan, en Kuwait el director general del Fondo Kuwaití para el Desarrollo Económico Árabe comunicó a las autoridades provinciales la aprobación del financiamiento por parte del directorio del organismo y se discutieron las acciones a emprender en pos de arribar a la firma del acuerdo que había comenzado a negociar la anterior gestión. Además, se organizaron rondas de negocios y se impulsó el diálogo sobre proyectos de obras de infraestructura para los sectores más vulnerables, de producción agropecuaria, biotecnología, deporte y turismo. En tanto, las reuniones organizadas en EAU tuvieron entre sus grandes ejes los siguientes temas: comercio, inversiones, financiamiento y la posibilidad de gestar acuerdos de cooperación.

Meses después el gobernador recibía en Rosario la visita protocolar del embajador de EAU, Mohammed Eissa Algattam Alzaabi, donde se hizo manifiesta la voluntad de las autoridades provinciales de avanzar con la apertura de una oficina comercial en Emiratos, en respuesta a la propuesta recibida por el gobernador durante su visita a Medio Oriente. Aún más, el embajador emiratí manifestó el interés de su país de intercambiar conocimientos en lo referente a las energías alternativas y renovables, un área en la que EAU posee amplia expertise, atendiendo a que el emirato ha promovido toda una serie de proyectos vinculados a una economía sustentable. El más publicitado de los mismos es Masdar City que apuesta a la creación de la ciudad con la menor huella ecológica. Entre otros avances que han tenido por escenario al citado país vale mencionar que allí abrió, en 2004, la primera planta de energía eólica del golfo. Asimismo, Emiratos acoge la mayor planta termosolar en operación en el mundo, Shams 1. Esto sin mencionar que el emirato es sede de
12. Cabe destacar que la tabla consigna únicamente el valor de las exportaciones con origen en Santa Fe y no las importaciones que han ingresados por aduanas santafecinas dado que el IPEC sólo brinda esta información de manera desagregada para los principales destinos desde los cuales la provincia importa, no encontrándose los países del golfo entre los mismos. 
la Agencia Internacional de la Energía Renovable (IRENA conforme sus siglas en inglés) y del Centro de Excelencia del Carbono de Dubai.

En tanto, en el mes de diciembre, el gobernador recibió al embajador de Kuwait en Argentina y a una comitiva del Fondo Kuwaití para el Desarrollo Económico Árabe que arribaron a Santa Fe para avanzar en las negociaciones por el crédito solicitado a dicha entidad e inspeccionar in situ el lugar donde habría de emplazarse la obra.

Mientras tanto, en una misión comercial que encabezó el gobernador en mayo de 2013 quedó inaugurada la Oficina de Representación de Santa Fe en Dubai. De esta manera, Santa Fe se convirtió en la primera provincia argentina con representación formal y permanente en EAU, transformándose la apertura de la misma en un importante logro y un resultado concreto de la paradiplomacia santafecina en relación con aquel país. La oficina, que depende del Ministerio de la Producción, encuentra entre sus funciones canalizar las ofertas de los empresarios de la provincia y dar respuesta a los requerimientos de los mismos, ya sea en cuanto a perfiles de mercado, datos sobre registración de mercancías o posibilidades de acceso a productos. Mientras que a esta representación también le incumbe el posterior armado de agendas de trabajo para que los empresarios locales puedan ir a ofrecer sus productos en forma directa.

Los instrumentos que pone a disposición la oficina revisten particular relevancia para todas aquellas empresas santafecinas que buscan encontrar un nicho en el mercado emiratí. No obstante ello, es menester destacar que pese a la labor de la misma su conformación no ha tenido un impacto mayor sobre el volumen de intercambio comercial entre las partes. En efecto, si consideramos el periodo bajo análisis, la tabla previamente presentada muestra que Santa Fe registró las mayores exportaciones hacia el mercado emiratí en 2010, cuando las mismas superaron los 124 millones de dólares, para luego reducirse progresivamente hasta alcanzar su punto de mínima en 2015, cuando las mismas apenas ascendieron a 11 millones de dólares (IPEC, 2017).

Vale destacar que, en función de las particulares características del territorio santafecino, que cuenta con algunas de las tierras más fértiles de todo el país y, como correlato, de su estructura productiva las principales exportaciones de la provincia a EAU han consistido en productos primarios, entre ellos cereales, semillas y frutos oleaginosos, además de manufacturas de origen agropecuario, carnes, lácteos, grasas y aceites. Mientras que a lo largo del periodo bajo estudio las exportaciones de manufacturas de origen industrial han resultado sumamente acotadas.

Dicho esto, se evidencia que pese a los logros que, como veremos a continuación, se han obtenido en lo referente a la búsqueda de financiamiento externo las acciones emprendidas con vistas a promover un incremento del intercambio comercial aún no han arrojado los resultados esperados. Si bien esto no supuso que la provincia dejase de emprender acciones con vistas a alcanzar tal fin; tal como puede constatarse al recordar que en febrero de 2014 una comitiva del gobierno provincial volvió a acompañar a un conjunto de empresas santafecinas que participaron de la $19^{\circ}$ edición de Gulfood. 
En línea con lo previamente referido, marzo de 2014 se convierte en una fecha importante pues tras casi dos años de espera y los reclamos pertinentes al Poder Ejecutivo Nacional, finalmente se autorizó que Santa Fe tomase el crédito negociado con el Fondo Kuwaití para el Desarrollo Económico Árabe brindándose los avales para que se concretase el desembolso ${ }^{13}$. En esta línea, se avanzó en la firma de tres documentos: el acuerdo de préstamo entre el Fondo y la provincia; de garantía entre el Fondo y el gobierno nacional; y un contrato de contragarantía entre la provincia y el gobierno nacional. Vale destacar que el crédito al cual Santa Fe tuvo acceso ascendió a 51 millones de dólares en tanto se previeron 4 años de gracia, 20 años de amortización, y una tasa de interés del 3\%. Así, fruto de años de negociaciones, dado que las primeras gestiones se habían efectuado durante el gobierno de Binner, se accedió a los recursos necesarios para concretar el Acueducto Reconquista que abastece de agua potable a 35 localidades del norte santafesino ubicadas en los departamentos General Obligado, San Javier y Vera, y tiene un área de influencia de $12.200 \mathrm{~km}$ cuadrados.

Todavía más, es dable destacar que este fondo no sólo ha firmado un acuerdo con Santa Fe sino que, más recientemente, en febrero de 2017, ha rubricado un convenio con la provincia de San Juan por medio del cual se pone a disposición un crédito de 50 millones de dólares con vistas a la financiación de parte del proyecto Acueducto Gran San Juan.

Dicho esto, cabe mencionar que la firma del acuerdo con Santa Fe se encuentra en línea con uno de los grandes pilares del "Plan estratégico provincial", básicamente aquel que apunta a la calidad social, la cual encuentra entre sus ejes el agua como derecho y oportunidad apuntando a preservar los recursos hídricos provinciales de manera integral, generando políticas de Estado que garanticen el acceso y el disfrute del agua (BONFATTI, 2012).

Aún más, otra reflexión insondable reside en que, a pesar de que el gobierno nacional ha intentado captar recursos de los vehículos financieros de las monarquías del golfo, presentando con tal fin decenas de proyectos ${ }^{14}$, los actores que finalmente se han beneficiado del financiamiento externo han sido los entes subnacionales. De hecho, como se verá a lo largo del trabajo, diversos gobiernos provinciales han recibido préstamos especialmente orientados a la realización de obras públicas. Estos datos otorgan un perfil singular a los vínculos económicos entre la Argentina y los actores del golfo en tanto estos últimos se han inclinado no ya por poner sus recursos a disposición del gobierno central sino de los actores subnacionales.

En esta misma dirección, con vistas a continuar obteniendo financiamiento para el desarrollo de infraestructura hídrica, en agosto de 2014 una misión institucional de la provincia visitó la sede del Fondo de la Organización de los Países Exportadores de Petróleo para el Desarrollo Internacional (Ofid) en Viena ${ }^{15}$. Allí se expuso la necesidad del gobierno de Santa Fe de obtener recursos para continuar extendiendo el sistema de acueductos provinciales y se dio cuenta del estado de avance de las obras.

De esta forma, mientras la primera etapa del proyecto del Acueducto Reconquista se llevó a cabo con recursos provinciales y con el ya referido
13. Al respecto, Zubelzú e Iglesias (2005) destacan que las provincias gozan de una autonomía que podría considerarse limitada en lo que refiere a la contratación de créditos con diversos actores internacionales si atendemos a que estas deben contar con la autorización de la nación ya sea como garante o como prestataria de los mismos. De esta forma, en lo que podríamos denominar como créditos "directos" la provincia es el prestatario inmediato y quien discute los términos y condiciones con el oferente, mientras el gobierno nacional es quien los garantiza. En tanto, en el caso de los créditos "indirectos" que involucran a la nación como prestataria, los mismos conllevan que esta última los transfiera a la provincia con un convenio subsidiario de préstamo.

14. Sin ir más lejos, la gira oficial que encabezó Fernández a Medio Oriente en 2011 resultó propicia para que Argentina presentase veinticinco proyectos a la Autoridad de Inversión de Kuwait (CIBEIRA, 2011).

15. El Fondo de la OPEP para el Desarrollo Internacional (Ofid) es una institución financiera de desarrollo cuya conformación fue impulsada por los Estados miembros de la OPEP en 1976 como un vehículo de ayuda a los países en desarrollo. El fondo apuesta a estimular el crecimiento económico y a luchar contra la pobreza en distintos escenarios. Con este objetivo provee financiamiento para desarrollar infraestructura básica, fortalecer la prestación de servicios sociales y de promoción de la productividad, la competitividad y el comercio. 
16. Entrevista efectuada a Débora Marini, Directora Ejecutiva de la Agencia de Inversiones y Comercio de la provincia de Santa Fe, Rosario, 10 mar. 2017.

17. El Fondo de Abu Dhabi es una entidad pública y autónoma que tiene como objetivo ayudar a los países en desarrollo a lograr un crecimiento socioeconómico sostenible por medio de la asistencia financiera en forma de préstamos concesionarios, la gestión de subvenciones públicas y de acciones. crédito del Fondo Kuwaití para el Desarrollo Económico Árabe, las negociaciones con la Ofid apuntaron a desarrollar la segunda etapa del mismo.

Las gestiones para la obtención de un nuevo crédito continuaron con una visita de representantes de dicha entidad a la provincia en el mes de octubre en la cual los mismos pudieron conocer la zona donde se emplaza el proyecto, los funcionarios a cargo de la ejecución del mismo, así como también indagar en la capacidad económico-financiera de la provincia. Poco tiempo después, en el mes de diciembre, el gobierno de Santa Fe recibió la aprobación del Ofid a la solicitud del préstamo. Y, finalmente, en febrero de 2015 el gobernador Bonfatti concretó la firma de un convenio de préstamos por 50 millones de dólares que tiene una tasa del $5 \%$ y un plazo de amortización de 18 años (14 de amortización más 4 años de gracia).

En otro orden, en paralelo a las acciones emprendidas con vistas a obtener financiamiento externo la provincia también buscó brindar herramientas para que las empresas santafecinas pudiesen abrirse camino en los mercados de Medio Oriente. De esta forma, en noviembre de 2016, el Ministerio de la Producción de Santa Fe organizó el primer Workshop de certificación Halal, una capacitación que tuvo por destinatarios a los actores interesados en establecer vínculos comerciales con EAU. Vale destacar que esta acción también se encontró en línea con el "Plan Estratégico Provincial" que expresa entre sus objetivos posicionar a las pequeñas y medianas empresas santafesinas en el mercado externo. Para lo cual el mismo prevé priorizar acciones tendientes a incrementar el número de empresas exportadoras que participen en el comercio exterior, exporten bienes de mayor valor agregado, diversifiquen sus productos y busquen nuevos mercados (BONFATTI, 2012). En este caso es clara la importancia de esta acción con vistas a que las PYMES locales puedan incrementar sus ventas a EAU y el mundo árabe en general atendiendo a que en la actualidad son muy pocas las empresas de la provincia que cuentan con esta certificación. De hecho, entre las mismas sólo puede darse cuenta de algunas empresas de gran porte como es el caso de Renova, así como también de una serie de empresas del sector cárnico. Por último, la exigencia de contar con esta certificación es concebida como una de las grandes barreras a sortear con vistas a acrecentar las exportaciones de manufacturas de origen agropecuario con mayor valor agregado ${ }^{16}$.

Mientras tanto, en febrero de 2017, representantes de la provincia de Santa Fe formaron parte de una misión institucional y comercial de la Región Centro a EAU, organizada por el CFI. La comitiva institucional estuvo encabezada por el vicegobernador de la provincia, Carlos Fascendini, en tanto también participó de la misma el ministro de Economía, Gonzalo Saglione. En esta oportunidad, una vez más, autoridades y empresarios participaron de la inauguración de la Feria Internacional Gulfood 2017. Mientras que la visita también contempló reuniones con miembros de las Cámaras de Comercio de Dubai y de Abu Dhabi, visitas al área del puerto y a la zona franca del emirato.

Aún más, la estancia en EAU fue propicia para continuar las negociaciones con representantes del Fondo de Abu Dhabi para el Desarrollo ${ }^{17}$ al que se le había solicitado un crédito de 80 millones de dólares que tendría por fin financiar la segunda etapa del Acueducto Desvío Arijón. 
Las negociaciones entre Santa Fe y el Fondo de Abu Dhabi se iniciaron con la presentación de una solicitud de apoyo financiero. Tiempo después, en marzo de 2016, tuvo lugar una reunión en Buenos Aires con el director de este organismo, Mohamed Saif Al Sawidi, tras la cual se logró la pre-aprobación del préstamo. A posteriori, en el mes de mayo, funcionarios del Fondo visitaron Santa Fe para controlar la documentación presentada, analizar la capacidad de pago de la provincia, así como también el esquema propuesto para la ejecución del proyecto. Es más, en aquella oportunidad se concretó una reunión con personal del Ministerio de Hacienda y Finanzas Públicas y la Jefatura de Gabinete con el objetivo último de debatir las características que debería presentar el acuerdo de garantía.

Lo cierto es que, en el mes de junio último, el gobernador de la provincia anunció la aprobación del crédito y el inicio del proceso de licitación para las obras de la etapa final del acueducto. Paralelamente se informó que el préstamo es a 15 años y con una tasa anual de 5\% anual. En tanto, conforme se dio a conocer, los fondos se desembolsarán de forma mensual en base a la certificación del avance en la ejecución de la obra ${ }^{18}$ (TELAM, 2017).

Para culminar este punto cabe agregar que este es el segundo préstamo que el Fondo otorga a una unidad subnacional argentina en tanto el primero fue recibido a principios de 2016 por la provincia de Neuquén. En dicho caso el financiamiento, por 15 millones de dólares, fue destinado a la construcción del proyecto hidroeléctrico multipropósito Nahueve. Asimismo, es importante subrayar que éste se ha convertido en el tercer organismo de crédito que brinda financiamiento al sistema de acueductos de la provincia conjuntamente con el Fondo Kuwaití para el Desarrollo Árabe y el Fondo de la OPEP para el Desarrollo Internacional.

Conclusión

Como se expuso a lo largo del trabajo, en el periodo que se extiende entre 2007 y 2017 la provincia de Santa Fe ha apostado por profundizar sus vínculos con Kuwait y EAU, dos países ubicados en torno al golfo Arábigo, a miles de kilómetros de distancia, que no se han caracterizado por ser socios tradicionales de la Argentina. Con tal fin se optó por sostener una presencia directa y se implementó un conjunto de acciones formales que en algunas oportunidades fueron coordinadas con el gobierno nacional y en otras tuvieron un carácter paralelo al accionar del mismo. Aún más, por tratarse de acciones que han tenido por destinatarios a países de otros continentes las mismas se convierten en un ejemplo de paradiplomacia global.

Al preguntarnos por el objetivo último de dichas acciones es claro que las mismas han perseguido intereses económicos vinculados a la recepción de inversiones, la búsqueda de financiamiento externo y la promoción del comercio.

Con las vistas puestas en tal fin se han organizado misiones comerciales e institucionales, rondas de negocios, ferias internacionales, se han recibido autoridades extranjeras e, incluso, han tomado lugar seminarios, sólo por mencionar algunas de las acciones en las que se ha plasmado la activa paradiplomacia santafecina.
18. Vale mencionar que, si bien reconocemos la importancia de sistematizar los datos respecto al total de inversiones y el monto en concepto de empréstitos recibido, no sólo por la provincia de Santa Fe, sino por la Argentina en su conjunto proveniente de los países árabes bajo estudio, dicha información no se encuentra disponible. En este sentido, como parte de la labor de investigación se buscó recabar estos datos a través del contacto así como también mediante la revisión de la información publicada por la Cámara de Comercio Argentino-Árabe y la Agencia de Inversiones de la provincia de Santa Fe sin resultado. Todavía más, la Agencia Argentina de Inversiones y Comercio Internacional posee en su sitio web un mapa de inversiones, no obstante, el mismo no arroja información respecto a los actores de la región de Medio Oriente. 
Ahora bien, en lo que respecta a los resultados de este accionar puede darse cuenta de importantes logros en lo referente a la obtención de financiamiento externo. Tal es así que la provincia rubricó un acuerdo de préstamo con el Fondo Kuwaití para el Desarrollo Económico Árabe por 51 millones de dólares y otro con el Fondo de Abu Dhabi para el Desarrollo por 80 millones de dólares que se destina a financiar la segunda etapa del Acueducto Desvío Arijón. Amén de ello Santa Fe ha avanzado en la firma de un acuerdo de hermanamiento con la provincia de Al Ahmadi, Kuwait, y se ha convertido en la primera provincia argentina en contar con una Oficina de Representación Comercial en Dubai. No obstante ello, es importante mencionar que los logros en materia financiera no se encuentran al mismo nivel que en materia comercial dado que el volumen de intercambio con estos países ha resultado magro y fluctuante aún pese a las potencialidades del mismo.

Referencias

BAILEY, Rob; WILLOUGHBY, Robin. Edible Oil: Food Security in the Gulf, EER BP, London, 2013.

BONFATTI, Antonio. Plan Estratégico Provincial Santa Fe. Visión 2030, Ministerio de Gobierno y Reforma del Estado de la Provincia de Santa Fe, Santa Fe, 2012.

BUSSO, Anabella; FABANI, Ornela. Los vínculos con Estados Unidos durante el menemismo y el kirchnerismo: su impacto en la inserción internacional y el modelo de desarrollo argentino. In. XII Congreso Nacional de Ciencia Política, Sociedad Argentina de Análisis Político, Universidad Nacional de Entre Ríos, Mendoza, 12 al 15 de agosto, 2015.

CALVENTO, Mariana. Análisis teórico-empírico de la gestión internacional de los actores subnacionales: una propuesta de abordaje para las ciudades intermedias, Confines, Bueno Aires, n. 20, agosto-diciembre, 2014, p. 35-58.

BAYLE, Rob. Edible Oil: Food Security in the Gulf, Chatman House,London, 1 nov.2013. Disponible en: https://www.chathamhouse.org/publications/papers/view/195281.Acceso en: 11 abr. 2018.

CIA, The world Factbook, 2017.

CIBEIRA, Fernando. Con el objetivo de seducir a los petrodólares, Página 12, Buenos Aires, 16 jan. 2011. Disponível em: $<$ https://www.pagina12.com.ar/diario/elpais/1-160549-2011-01-16. html> Acesso en: 30 mar. 2018.

COLACRAI, Miryam y ZUBELZÚ, Graciela. Las Vinculaciones externas y la capacidad de gestión internacional desplegada por las provincias argentinas en la última década. Una lectura desde las relaciones internacionale. In. VIGEVANI, Tullo. A dimensão subnacional e as relações internacionais, São Paulo, UNESP, 2004.

ARGENTINA, Constitución(1994), Constitución Nacional de la República Argentina, Buenos Aires, Corte Suprema de Justicia de la Nación (Argentina),2017, p. 1-263.

DE MARSILIO, Ernesto. Aportes teórico - metodológicos para el estudio de las relaciones paradiplomáticas. Qué, quiénes y cómo: Análisis del caso argentino, en Serie Breviario en Relaciones Internacionales, Maestría en Relaciones Internacionales del CEA-UNC, Córdoba, Argentina, 2006.

ESPERANZA DÍA POR DÍA. Bonfatti anunció un plan de financiamiento para obra pública, Esperanza, Santa Fe, 7 ago. 2012. Disponible en: $<$ http://www.esperanzadiaxdia.com.ar/bonfatti-anuncio-un-plan-de-financiamiento-para-obra-publica-por-500-millones-de-dolares . Acceso en: 30 mar. 2018

DUCHACEK, Ivo. The International Dimension of Subnational Self-Government, The Journal of Federalism, Oxford, Publius, 1984.

FABANI, Ornela. El devenir de las relaciones entre Argentina, Emiratos Árabes Unidos y Qatar durante los gobiernos de Cristina Fernández (2007-2015): vínculos modestos en evolución, Revista de Estudios Internacionales Mediterráneos, n.21, 2016, p. 119-140. 
FABANI, Ornela. "Un acercamiento a socios no tradicionales: la evolución del vínculo entre la Argentina y las monarquías del golfo durante las administraciones de Cristina Fernández (2007-2015)", JANUS, Universidade Autónoma de Lisboa, v. 6, n. 2, 2015, p. 16-31.

FRONZAGLIA, Mauricio. Unidades subnacionais: um estudo de caso sobre a cidade de São Paulo - de 2001 a 2004, Tesis de Maestría, Campinas, UNICAMP, 2005.

GARCÍA SEGURA, Caterina. La Actividad Exterior de las Entidades Políticas Subestatales, Revista de Estudios Políticos (Nueva Época), Centro de Estudios Políticos y Constitucionales, n. 91, Madrid, 1996, p. 235-264.

GOBIERNO DE SANTA FE. Binner se reunió con embajadores de los países árabes en la Argentina, Santa Fe Avanza, 3 dez. 2008. Disponible en: < http://gobierno.santafe.gov.ar/prensa/mitemplate.php?idnoticia $=69500 \&$ mostrarmenu $=$ si\&include $=$ noticias_prensa $/ 2008 / 031208 \mathrm{~s} 22$. htm $\&$ ptitulo=Noticia $\% 20 \mathrm{del} \% 20 \mathrm{mi} \%$ E9rcoles $\% 203 \% 20 \mathrm{de} \% 20$ diciembre $\% 20 \mathrm{de} \% 202008 \% 20$ $(031208 \mathrm{~s} 22 . \mathrm{htm}) \&$ fechanoticia $=\&$ volverurl $=\& \mathrm{pDescDiaMax}=$ Lunes\&intvalDiaMax $=23 \& \mathrm{pD}$ escMesMax $=$ junio $\&$ A\%F1oMax $=2008 \&$ DiaMax $=23 \&$ MesMax $=06 \&$ pdia $=03 \& \mathrm{pmes}=12 \& \mathrm{pan}$ io $=2008$. $>$ Acceso en: 30 mar. 2018.

CAMARA DE COMERCIO DE SANTA FE. Oportunidades de comercio e inversiones entre Santa Fe y el mundo árabe. Estado de Kuwait y Emiratos Árabes Unidos, Rosario, 28 abr. 2011. Disponible en< http://www.comercioexterior.org.ar/nota/1005-oportunidades-de-santa-fe-en-el-mundo-arabe.html> Acceso en: 30 mar.2018.

GOBIERNO DE SANTA FE. La nueva estrategia productiva para Santa Fe, Gestión del Gobernador Hermes Binner, Repaso de lo actuado y propuestas a futuro, Documento de Trabajo, Santa Fe, 2011.

IGLESIAS, Valeria. Las provincias y su gestión en el área de comercio exterior. Diagnóstico y análisis del caso argentino.In. IGLESIAS, Eduardo. Las provincias argentinas en el escenario internacional. Desafíos y obstáculos de un sistema federal, Programa de las Naciones Unidas para el Desarrollo (PNUD), Buenos Aires, 2008.

INFOCAMPO. Santa Fe tendrá una oficina comercial en Emiratos Árabes, Santa Fe, 21, may. 2013. Disponible en: < http://www.infocampo.com.ar/page/2003/?titulo=En-el-ultimo-mes-los-precios-minoristas-de-la-carne-subieron-un-40\&id_nota $=20111 \& p=$ ver_nota\%2522.> Acceso en: 30 mar.2018

INSTITUTO DE FOMENTO REGIONAL DE MURCIA . Informe País: Kuwait,2014. Disponible en: < http://www.institutofomentomurcia.es/> Acceso en: 30 mar. 2018.

INSTITUTO PROVINCIAL DE ESTADÍSTICAS Y CENSO (IPEC). Exportaciones e Importaciones, Santa Fe, 2017. Disponible en: <https:/www.santafe.gob.ar/index.php/web/content/ view/full/111313/(subtema)/93664>. Acesso em: 30 mar.2018.

KINCAID, John. Constituent diplomacy in federal polities and nation-states as foreign policy actors. In. MICHELMANN, Hans; SOLDATOS, Panayotis. Federalism and International Relations. The role of subnational units, Oxford, Claredon Press Oxford 1990, p. 54-75.

MELTZER, Joshua, HULTMAN, Nathan, LANGLEY, Claire. Low-Carbon Energy Transitions in Qatar and the Gulf Cooperation Council Region, Brookings Institution, Washington, 2014. Disponible en: <http://www.brookings.edu/research/reports/2014/03/low-carbon-energy-transitions-qatar-hultman-meltzer>. Acceso en: 30 mar. 2018.

MINISTERIO DE RELACIONES EXTERIORES . Información de Prensa $\mathbf{n}^{\circ}$ 028/14, Buenos Aires, 14 feb. 2014. Disponible en: <https://www.mrecic.gov.ar/mision-de-comercio-e-inversiones-paises-arabes-del-golfo $>$. Acceso en: 30 mar. 2018.

OFICINA ECONÓMICA Y COMERCIAL DE ESPANA EN DUBAI. Guía País: Emiratos Árabes Unidos, Madrid, 2014. Disponible en: <http://www.comercio.gob.es/tmpDocsCanalPais /2902DBEB59D661E629CE0837AE19429F.pdf >. Acceso en: 30 mar. 2018.

PAUSA. La obra pública necesita crédito, Buenos Aires, 13 oct. 2014. Disponible en: <http:// pausa.com.ar/2014/10/la-obra-publica-necesita-credito/.> Acceso en: 30 mar.2018

ROSENCRANCE, Richard. El ascenso del Estado comercialista: comercio y conquista en el mundo moderno, Madrid: Ed. Alianza, 1986.

SECRETARÍA DE COMUNICACIÓN PÚBLICA. Timerman entregó los Premios Exportar y anunció un nuevo récord de ventas al exterior, Buenos Aires, 21 dez. 2011. Disponible en: $\quad<$ http://prensa.argentina.ar/2011/12/21/26742-timerman-entrego-los-premios-exportar-y-anuncio-un-nuevo-record-de-ventas-al-exterior.php>. Acceso en: 30 mar. 2018

SECRETARÍA DE RELACIONES INTERNACIONALES E INTEGRACIÓN. La internacionalización de la Provincia de Santa Fe. Estrategias y avances, Santa Fe, 2011-2015, 2016. 
SILES, Matías. La paradiplomacia de las provincias argentinas y la responsabilidad internacional derivada de su actuación. In. VII Congreso de Relaciones Internacionales del Instituto de Relaciones Internacionales de la UNLP, La Plata, 26 al 28 de noviembre de 2014.

SOVEREIGN WEALTH FUND. Funds Ranking, 2015. Disponible en: $<$ http:// www.swfinstitute.org/fund-rankings/ > Acceso en: 30 mar.2018.

TELAM. Llega un crédito por U\$\$ 80 millones de un emirato árabe para terminar un acueducto, Santa Fe, 25 jun. 2017. Disponible: < http://www.telam.com.ar/notas/201706/193448-credito-de-un-emirato-arabe-para-acueducto.html>. Acceso en: 30 mar. 2018

UNO SANTA FE. El gobierno provincial pide elevar el monto de endeudamiento para financiar obra pública, Santa Fe, 06 may. 2016. Disponible en: < https://www.unosantafe.com. ar/santafe/el-gobierno-provincial-pide-elevar-el-monto-endeudamiento-financiar-obra-publica-n884935.html. Acceso en: 30 mar.2018.

VIGEVANI, Tullo. Problemas para atividade internacional das unidades subnacionais, Revista Brasileira de Ciencias Sociais, São Paulo, v. 21, n. 62, 2006.

ZUBELZÚ, Graciela. Primer Informe, Programa Provincias y Relaciones Internacionales, Consejo Argentino de Relaciones Internacionales (CARI), Programa de Naciones Unidas para el Desarrollo (PNUD), Buenos Aires, 2004.

ZUBELZÚ, Graciela y IGLESIAS, Valeria. Segundo Informe Relevamiento y Diagnóstico, Comité de Provincias en el Plano Internacional del Consejo Argentino de Relaciones Internacionales (CARI), Programa de Naciones Unidas para el Desarrollo (PNUD), Buenos Aires, 2005. 